\title{
Crimen y castigo en la Tercera Celestina de Gaspar Gómez de Toledo: ¿la visión moralizadora de un médico?
}

\author{
Folke Gernert \\ Universität Trier
}

\section{RESUMEN}

El presente artículo estudia la Tercera Celestina de Gaspar Gómez de Toledo como obra escrita posiblemente por un médico haciendo particular hincapié en las textualizaciones del saber curativo desde una perspectiva de la historia de la ciencia. Una comparación con La Lozana Andaluza del médico Francisco Delicado muestra paralelismos con la obra de Gómez de Toledo, quien, al igual que el galeno andaluz, emite juicios moralizantes a través de la metáfora de la enfermedad y de la minusvalía física.

Palabras Clave: Literatura y medicina, Disability Studies, La Lozana Andaluza, La tercera Celestina, Continuaciones de la Celestina

\section{Crime and punishment in Tercera Celestina by Gaspar Gómez de Toledo: a doctor's moralising view?}

\section{ABSTRACT}

The present article studies the Tercera Celestina by Gaspar Gómez de Toledo as a work possibly written by a physician, placing particular emphasis on the textualisations of healing knowledge from a perspective of the history of science. A comparison with La Lozana Andaluza by the doctor Francisco Delicado shows parallels with the work of Gómez de Toledo who, like the Andalusian physician, makes moralistic judgements through the metaphor of illness and physical disability.

Keywords: Literature and medicine, Disability Studies, La Lozana Andaluza, La tercera Celestina, Continuations of the Celestina 
La Tercera Celestina es un libro 'raro' - eso dice Menéndez Pelayo y razón no le falta. Hablando de las continuaciones de la obra de Rojas, el santanderino dictamina que la obra de Gaspar Gómez de Toledo «es la más rara de esta serie de libros, aunque a esta rareza se reduce todo su mérito» (1943: 80-81). Es de sobra conocido que a don Marcelino no le gustaba nada este libro que llama «necia y soporífera composición» (1943: 82) y la «insípida rapsodia de Gaspar Gómez» (1943: 90). Otra obra 'rara' que se puede leer en cierta medida como continuación de la Tragicomedia es la Lozana Andaluza de Francisco Delicado ${ }^{1}$ que se publicó unos ocho años antes que la obra de Gaspar Gómez. Esta especie de 'novela dialogada' gustó aun menos a don Marcelino:

La Lozana, en la mayor parte de sus capítulos, es un libro inmundo y feo, aunque menos peligroso que otros, por lo mismo que el vicio se presenta allí sin disfraz que le haga parecer amable. Es un caso fulminante de naturalismo fotográfico, con todas las consecuencias inherentes a este modo de representación elemental y grosero, en que la realidad se exhibe sin ningún género de selección artística y hasta sin plan de composición ni enlace orgánico. Con saber que llegan a ciento veinticinco los personajes de esta fábula, si tal nombre merece, puede formarse idea del barullo y confusión que en ella reina. (Menéndez Pelayo 1943: 54)

No es sólo el rechazo por parte de Menéndez Pelayo lo que estas dos obras que fueron escritas más o menos por las mismas fechas comparten. Aunque es poco probable que Gaspar Gómez pudiera haber tenido acceso a la Lozana Andaluza, una obra que parece haber desaparecida nada más ser impresa ${ }^{2}$, hay una serie de paralelismos como el plurilinguismo ${ }^{3}$ que tienen en común con las comedias a noticia de Torres $\mathrm{Naharro}^{4}$, el incremento del número de capítulos frente a la obra de Rojas (50 autos y 66 mamotretos) y, quizás lo más destacable, el gran número de personajes que aparecen en ambas obras. La Tercera Celestina no llega ni de lejos a los aproximadamente 125 personajes de la Lozana Andaluza que -según

1.- El subtítulo del Retrato reza: «y contiene munchas más cosas que la Celestina», Delicado, La Lozana Andaluza, eds. Joset \& Gernert (2013: 3); véase para la influencia de la Celestina en la obra de Delicado Salvador Miguel (1984), Botta (2002) y Villagrá Terán (2013).

2.- Véanse Menéndez Pelayo (1943: 57) y Gernert (1999: 46-48).

3.- Véase para la obra de Gaspar Gómez Menéndez Pelayo (1943: 89): «Son varias las jerigonzas usadas en esta pieza. Además de la negra Boruga, que ya estaba en Feliciano de Silva, hay un vizcaíno, Perucho, mozo de caballos de Felides, que habla siempre en castellano chapurrado y entona una canción que al parecer está en vascuence [...]».

4.- Véanse Cirillo (1988) y el prólogo de Gernert en Delicado, La Lozana Andaluza, eds. Joset \& Gernert (2013: XVII). 
Menéndez Pelayo- causan «barullo y confusión» ${ }^{5}$. Asimismo, investigadores como Navarro Durán reprenden «la multiplicación de personajes secundarios sin entidad» (2016: XXXIV) en la continuación de Gómez de Toledo. Es el mundo del hampa que gana en protagonismo en la Tercera Celestina, en la que proliferan los personajes de los bajos fondos. En el presente trabajo me interesa contextualizar la representación del mundo marginado en la obra y estudiar las particularidades de la protagonista, y forma y función de los castigos que sufre.

\section{Los vicios de la tercera Celestina}

En la Segunda Celestina, el lector tiene que esperar hasta la VII Cena a que aparezca resucitada la vieja alcahueta. En la obra de Gaspar Gómez es sólo en el auto XII en el que Celestina se persona por primera vez. Y lo hace con un monólogo que introduce una de las características más llamativas del personaje, su afición al vino:

¡Oh gloria sea a Dios que han visto mis ojos tiempo tan deseado de tal abundancia de vino que lleva hombre una cántara por menos de lo que le solía costar un azumbre! Y ansí goce yo de mis canas que tuve razón en reñir anoche con aquel suzuelo de arcaller, porque le encargué cincuenta veces que me hiciese de cuatro azumbres este cangiloncillo, y no sacaba poco más de tres. Mas ansí pasaré mi laceria repartiéndolo en comida y cena mientras otro se hace que sea mayor, y no mirando a la regla que manda tres postetas en cada asentada. Yo no sería Celestina si no la quebrantase reglándome con azumbre y medio en seis, que, aunque no es para matar la sed la copa de un cuartillo, sufrirá la persona su desventura; que todo lo hace aforramos. en la santa taberna para cumplir las faltas que en la comida tuviere ${ }^{6}$.

La enorme sed de las alcahuetas literarias es un lugar común desde la Antigüedad clásica ${ }^{7}$. Tampoco la primera y la segunda Celestina o la Loza-

5.- Véase para este número asimismo Allaigre (2004).

6.- Gómez de Toledo, Tercera parte de la tragicomedia de Celestina XII, ed. Navarro Durán (2016: 442-443).

7.- Véase Barrick (1973: 8): "Celestina's fondness for wine is a trait which she acquires only in Rojas' later additions to his work, but it was a trait of many of the bawds in Roman literature. In view of the frequent references to Celestina's thirst in the original Celestina, it is not strange that the Celestina-figures of the imitations should also be imbibers. Silva's Celestina enrages her compatriots by her drinking, and Gerarda in La Dorotea also carries the vice to excess. The Celestina in Gómez' continuation upholds the tradition adequately. Like the original Celestina [...] and the later Dolosina, she discourses on the virtues of wine [...]». 
na desdeñan el caldo de uva, pero los respectivos autores insisten mucho menos en esta faceta y renuncian a reproches en boca de otros personajes.

$\mathrm{Al}$ igual que la protagonista de Rojas u otras mujeres marginadas, la tercera Celestina es llamada «la barbuda» o «aquella barbuda» (2016: 441, 474 y 542), sin que el hirsutismo femenino - ausente, por cierto, en Feliciano de Silva - tuviera las implicaciones que presenta en otras obras de la misma índole ${ }^{8}$. La lujuria no es uno de los vicios de los que la tercera Celestina sea culpable. Además de su debilidad por el vino, la avaricia y la codicia son las características negativas más llamativas de la rufiana de Gaspar Gómez. Se trata del vicio proverbial de este grupo profesional, que también Pietro Aretino describió con gran lujo de detalle en sus Ragionamenti.

La fealdad moral de la mujer pecadora se refleja y exterioriza en su fealdad física y corporal como se desprende del retrato que pinta Areúsa de su «tía»:

Yo te prometo, más años tiene a cuestas que dos los más antiguos del pueblo. Y esto sin jurarlo se vee en ella por experiencia; que tiene ya los ojos hundidos, las narices húmidas, los cabellos blancos, el oír perdido, la lengua torpe, los dientes caídos, la cara arrugada, los pies hinchados, los pechos ahogados. En conclusión, es mi pensar que, si la sepoltura hablase, como acá será suya, la compelería por justicia a que fuese a poblar su casa. (Gómez de Toledo XVI, 2016: 497) ${ }^{9}$

Como observa con acierto Pitel, el aspecto repulsivo de las viejas alcahuetas suscita «desprecio y aversión a su alrededor» (2011: 189) ${ }^{10}$. El paje Albacín insiste en que la vejez y la decrepitud física no están en absoluto reñidos con la depravación:

Por eso es cosa admirable de ver, y aún digna de notar, en que todas las cosas corporales del hombre se envejecen si no es el corazón interior y la lengua exterior, porque el corazón siempre está verde para pensar maldades, y en la lengua jamás falta habilidad para decir mentiras y malicias, como vemos en su merced. (Gómez de Toledo XVI, 2016: 497)

8.- Véase para el hirsutismo como signo de lascivia femenina Juárez-Almendros $(2018,91)$ y Gernert (2018a: 424-428 y 2018b: 261-265).

9.- Véase para retratos literarios de mujeres ancianas en la literatura española Snow (2005) y para la literatura italiana Bettella (2005).

10.- Véase para el desprecio de la vejez femenina Diochon \& Iglesias (2011) y JuárezAlmendros (2018: 84): «In contrast with the cultural representation of old men, which mostly emphasizes attributes of wisdom and dignity, descriptions of old women center on their corporeal decay and moral depravity». Para la vejez en la Celestina de Rojas véase Lizabe (2010). 
El hirsutismo y la fealdad de las viejas alcahuetas se asocian en muchos textos no sólo con la maldad sino también de forma más concreta con la dedicación a la magia ${ }^{11}$. La fealdad de la tercera Celestina no es demoníaca, sino es más bien indicativo de su caducidad e indefensión.

No es el lugar de entrar en la controvertida cuestión sobre el estatus de la magia en la obra de Fernando de Rojas. Como observa acertadamente Barrick: «later Celestina-figures take advantage of popular credulity, using it to their own benefit, but they give little evidence of believing in magic themselves» (1973: 6). Se puede añadir que tanto la Lozana Andaluza como las mujeres marginadas de Pietro Aretino se caracterizan por esta misma actitud, mientras que "[1]a Celestina resucitada en la obra de Feliciano de Silva rechaza explícitamente el uso de la magia para intervenir en los amores de Felides y Polandria» (Baranda Leturio 2017: 69).

A pesar de que la tercera Celestina sea llamada «hechicera» por otros personajes ${ }^{12}$, no practica en ningún momento las artes prohibidas que tienen un cierto protagonismo en otras obras celestinescas. La creencia en la eficacia de la hechicería es presentada como indicio de ingenuidad y cobardía: No sorprende que sea Pandulfo quien teme los supuestos poderes de la vieja:

¡Descreo de Mahoma, si de verdad lo supieses, si no hicieses más de lo que dices!, porque ella es tan marcada en hacer unos encantamientos, ique por Nuestra Señora!, que al más desuellacaras que a ella se allegue, hace de arte que le torna humilde y honesto, siendo la renegada indómita y soberbia; y al rufián que en su vida supo dar a su puta sino dos mil azotes, tiene modo de volverle benívolo y amoroso, usando la señora de su desenfrenada envidia y maldita codicia; y el que en sus días no sufrió palabra, busca modos de tornarle cuerdo y sufrido, viendo claro cuán loca e impaciente es; y el que jamás usó de dar una sed de agua a su iza, sino pelarla como a pájaro, tiene encestamientos con que le hace ser liberal y magnánimo, Y averiguado toda la escaseza y malicia reina en su cuerpo. En conclusión, puedes creer que al bellaco que no cae, ante omnia con un certum quid, ella le amonesta tales sermones que, aunque esté cursado en caminar aposta, le atraerá que sea continente y casto,

\section{1.- Véase Sanz (1994: 23-33).}

12.- Así lo hacen Rodancho, en el auto doce (2016: 442), Albacín la llama «puta hechicera» (2016: 497) y Barrada se dirige a ella como «doña hechicera» (2016: 542). Rodancho recuerda, además, el famoso conjuro en la obra de Rojas cuando dice: "Ora, di lo que quisieres; que, pues me has metido en el juego, no sería yo Rodancho si a cenar no la enviase con su amigo Plutón» (2016: 441). 
probando ser ella disoluta en sus obras y lujuriosa en deseo; y por tanto, si gravemente los viejos son castigados, más es por el mal enjemplo que dan que por la culpa que cometen. (Gómez de Toledo XII, 2016: 441-442)

En la séptima pregunta de la primera parte del Malleus maleficarum se delibera «si los demonios, por intermedio de las brujas, pueden alterar o incitar a los espíritus hacia el amor o el odio desordenados» (Kramer \& Sprenger 2006: 125) y la respuesta es negativa porque 1) sólo Dios puede cambiar sus propias criaturas ${ }^{13}$, 2) el diablo no puede conocer los "pensamientos íntimos» de los hombres ${ }^{14}$ y 3 ) no tiene poder sobre el libre albedrío de los hombres ${ }^{15}$. Desde un punto de vista demonológico, los temores de Pandulfo son un disparate y semejante creencia ridiculiza a quien la tiene. Además, por razones de verosimilitud, no se explicarían los ataques que sufre la protagonista a lo largo de toda la obra si tuviera poderes sobrenaturales. Ella aparece en repetidas ocasiones como víctima que no dispone de ningún instrumento ni mágico ni retórico para defenderse.

\section{Celestina castigada}

La particularidad más llamativa de la Tercera Celestina es indudablemente la acumulación de castigos físicos que sufren la protagonista y otros personajes, sobre todo femeninos. Piénsese en la muerte violenta de Areúsa, la perdida de un brazo de su amante Bravonel y el maltrato de la prostituta Ancona por parte del rufián manco ${ }^{16}$, episodio que Navarro Durán desestimó como "otro despropósito» (2016: XXXVI). Aunque no siempre se puede evitar la tentación de (des)calificar la obra con Menéndez Pelayo de necedad, hay que tratar de dar sentido al texto desde su contexto e intentar explicar el porqué de esa acumulación de agresiones

13.- "aquel que crea que una criatura puede ser transformada para mejor o para peor, o convertida en otra forma o apariencia, salvo por el Creador de todas cosas, es peor que un pagano y un hereje» (Kramer \& Sprenger 2006: 126).

14.- «Si [...] el diablo pudiera afectar el amor y el odio, podría observar los pensamientos íntimos. Y de nuevo: no todos nuestros malos pensamientos provienen del diablo; a veces se originan en nuestra voluntad» (Kramer \& Sprenger 2006: 126).

15.- «amor y odio son materias de la voluntad, cuyas raíces se encuentran en el alma; por ello, con ningún artilugio pueden ser causados por el demonio. La conclusión, como afirma san Agustín, es que sólo Aquel que creó las almas es capaz de internarse en ellas. Mas aún: es incorrecto afirmar que, puesto que el maligno puede influir en las emociones, entonces puede regir la voluntad» (Kramer \& Sprenger 2006: 126).

16.- «Bravonel: ¡Toma, toma! Veamos si la despedazarás. Ancona: ¡Ay! ¡Ay! iJusticia! ¡Justicia! ¡Que me ha bañado en sangre! ¡Ay, muelas quebradas! ¡Malvado!, ¿qué te he hecho que ansí me tratas? Acabote de dar lo que tengo, y dasme esto en pago por ser tan perverso como eres. Te he sofrido cada día tus bellaquerías secretas por que no me lastimases en público». (Gómez de Toledo XLIV, 2016: 650). 
físicas. Hinrichs quien llama a Gómez de Toledo «a brilliant writer of the end» (2010: 84) $)^{17}$ es el investigador quien se ha ocupado más en detalle del «most physically abused character of her age, equalled perhaps only by Lazarillo and exceeded perhaps only by Don Quijote» (2010: 86).

Nada más aparecer, Celestina es agredida por Pandulfo y Rodancho y lesionada gravemente la pierna ${ }^{18}$. La alcahueta pierde la conciencia y no la recupera ni siquiera cuando Rodancho le echa vino encima ${ }^{19}$. Hinrichs interpreta esta escena en términos de una contrapasso dantesco muy sui generis:

This poetic (in)justice complements those scenes by punishing Celestina with the material of her favored vice. Here the wine consumption is inverted: The earlier ingestion is turned outwards as the wine is poured on her, not in her. It is the first of many instances where Gómez complements Rojas and Silva by turning the inward, indoors and private aspects of their works, outward, outdoors and public. (Hinrichs 2010: 88)

El investigador estadunidense que presta mucha atención a las agresiones que sufre la Celestina de Gómez de Toledo relaciona este primer castigo con el segundo, infligido por Barrada en el auto XXVI ${ }^{20}$. En este episodio repugnante el autor juega con el horizonte de expectativas del lector que en un principio no se puede imaginar qué castigo ignominioso está tramando el rufián engañado cuando dice en un soliloquio: «evitando pláticas, me cumple a revolver el cabo de esta tripa a la mano, porque, desque le dé recio, saltará la flema que dentro tiene, y no querría por dos doblas que me alcanzase parte del rocío; que, demás del olor, dudo no quedar mancha en la ropa que cayere» (Gómez de Toledo XXVI, 2016: 497). Cuando lo pone en práctica, ya no cabe duda en qué consistía el plan:

\section{Celestina: ¡Ay, ay, ay! ¡Santa María, váleme, que me han cegado!}

17.- Comparte esta valoración positiva con Criado de Val quien lamenta la «mala fortuna literaria» (1976: XLVIII) de la obra, cuya lectura, según él es «un auténtico placer» (1976: XLIX). Véanse para el "nacimiento crítico del "género" celestinesco" Baranda Leturio \& Vian Herrero (2007) quienes, de hecho, prestan poca atención a la obra de Gómez de Toledo.

18.- «RoDANCHO: ¡Tira por ahí arriba! No nos detengamos aquí, que descreo del diablo si no la quisiera hacer el cuerpo harnero; no obstante que queda la una pierna cortada y aun que la herida no es mocosa». (Gómez de Toledo XII, 2016: 444).

19.- «RodAnCHo: Qué más sino que, cuando allegué, estaba sin habla y tan sin sentido como muerta. Y por cumplir mi promesa, dende la cabeza hasta los pies la bañé en el vino, y en lugar de coroza la atesté muy bien el jarro encima de los tocados». (Gómez de Toledo XII, 2016: 445)..

20.- «First she was nearly drowned in wine, now she is nearly blinded with feces - "enmerdado" - another instance of incontinent ingestion narrated in Silva turned outwards in Gómez. It is a neat if foul poetic justice that the man who provided Celestina with food now uses its end result to punish her abuse of his trust». Hinrichs (2010: 89). 
BARRADA: ¡Voto a la casa de Meca, que mejor digas enmerdado! Y hagamos cuenta con tu bolsón; que tienes olorosa la persona. (Gómez de Toledo XXVI, 2016: 543)

Como observa con acierto Hinrichs, el autor «slows the narrative down to take it in fully from various perspectives» (2010: 89). A continuación, la degradación del personaje se ve reforzada por la actitud de los rufianes Bravonel y Grajales quienes encuentran su cuerpo profanado:

Bravonel: ¡Oh descreo de Plutón, y cómo has acertado!, que sin duda ella está con duelos.

Grajales: Álzala de ese brazo. Veremos qué mal tiene o si está herida.

Bravonel: ¡Pese a tal con quien te parió!, porque del arte que está envestida en suciedad tan clara, iy me digas, excusándote tú, que la mire yo!

Grajales: No lo dije por tanto, que yo huelgo de lo hacer; iy nota si me excuso!

BraVonel: ¡Cuerpo de Santiago, y qué hedentina tiene, demás de estar tan empringada en ello!

Grajales: ¡No me ayude Dios si no fue notable la bacinada y el castigo!

Bravonel: ¡Voto a Mares! ¿Qué es sino muy gentil tripa de vaca, que, dándola de butagazos, rompió y echó de sí el caldo espeso que tenía? ¡Y aun puedes creer que era hombre cursado en el oficio el que la maltrató! (Gómez de Toledo XXVI, 2016: 547)

El rufián Bravonel se hace portavoz de un colectivo hampesco que considera semejante castigo ignominioso como una expresión de destacadas habilidades profesionales ${ }^{21}$. El episodio se inscribe en una serie de narraciones escatológicas. Recuérdese que Rampín, el marido-criado de la Lozana cae en una letrina ${ }^{22}$, como lo hizo Andreuccio da Perugia en la quinta novella del segundo día del Decameron. En la picaresca posterior se producen no solo caídas en estercoleros ${ }^{23}$ sino se narran igualmente burlas pesadas en las que los pícaros acaban embarrados en excrementos. Núñez Rivera (2010: 174-175) recuerda sendos episodios del Guzmán de Alfarache y del Buscón en los que los pícaros desprevenidos se acuestan en un lecho lleno de estiércol. Lo impactante de estas narraciones, como en el caso de Gómez, es el hecho de que no se trata de accidentes, sino de actos inten-

21.- Véase, para el personaje de Bravonel, Barrick (1973: 27).

22.- Delicado, La Lozana Andaluza XXXIII, eds. Joset \& Gernert (2013: 168).

23.- Véase Núñez Rivera (2010). 
cionados llevados a cabo con premeditación y alevosía. La Tercera Celestina es -a que yo sepa- la única obra en la que una mujer es víctima de semejante mortificación. ¿Cual es la razón de ser de este castigo repulsivo digno de Rabelais y Quevedo? Recuerda mutatis mutandis las narraciones de violaciones colectivas de prostitutas en la literatura licenciosa italiana y en La Lozana Andaluza, conocidas como trentuno o trentón ${ }^{24}$. Se trata igualmente de un castigo atroz, infligido para sancionar la deslealtad femenina. Volviendo a la Tercera Celestina, es preciso recordar que la protagonista sufre una tercera agresión: En el auto XXXVII es el paje Albacín, enamorado de Elicia, quien cruza la cara a Celestina para vengarse de ella ${ }^{25}$. Las cuchilladas en la cara son populares en el hampa literario que deja a los sancionados señalados de por vida ${ }^{26}$. El asaltante regresa a la escena del crimen, disimulando su implicación y dirigiéndose a Celestina con cierta sorna: «¿Cómo estás ansí, madre? ¿Qué traición ha sido esta? Nunca te ha de faltar una desdicha: o la pierna cortada, o la cara cruzada; que antes que de uno sanes, te viene otro" (XXXVII, 2016: 611). Esta especie de recordatoria sirve para enfatizar que la protagonista ha sido víctima de violencia física en repetidas ocasiones. Mientras que Albacín destaca solamente el hecho en sí, uno de los vecinos de Celestina explica las desgracias del personaje como consecuencia de sus maldades actuando -según observa acertadamente Hinrichs (2011: 90)- como un coro:

VeCIno: Por lo que juraste, te diremos lo que cada uno supiere; $y$ es que, hablando contigo la verdad, si Pandulfo te hirió, no fue por lo que nosotros hecimos. Si Barrada te afrentó y robó, tú hemos sabido que le habías hecho por qué. Si Albacín te cruzó la cara y se llevó a tu sobrina Elicia, tus murmuraciones e impedimentos que no la hablase lo causaron; que claro está que un rapaz como aquel paje no se había de atrever a tal cosa, sino que muchas veces la demasiada razón causa sobrado atrevimiento. Ansí que no te quieras hacer ignorante de este hecho; que no lo decimos ante la justicia, sino como entre padres e hijos; que bien víamos entrar y salir a Bravonel, un rufián que en tu presencia abrazaba Areúsa el otro día; y si tú no consintieras su yerro, Grajales no la diera agora tal castigo. Y si no es ansí como lo hemos dicho, di tú lo que quisieres, que,

\section{4.- Véase Gernert (1999: 141-145).}

25.- «Albacín: Descreo de la vida si no tengo de cruzar hoy la cara a Celestina, aunque la aguarde por aquí hasta la mañana; que tan perversa vieja menester es que de todos sea castigada, pues jamás se escarmienta» (Gómez de Toledo XXXVII, 2016: 609).

26.- Véase para las cicatrices en la Segunda Celestina y en otros textos afines Gernert (2018a: 422-424). 
por que no te venga daño, lo concederemos. (Gómez de Toledo XL, 2016: 630)

Esta incriminación que recuerda al lector los pecados de Celestina precede la aparición del corregidor que la culpa de la muerte de Areúsa ${ }^{27}$ y la condena a la vergüenza pública:

CORREGIDOR: Hora, Balantes, no se tome más información de la tomada, ni se haga más pesquisa de la hecha; sino luego haz venir al pregonero. Que yo doy por sentencia que, desde aquí que se cometió el delito, saquen a Celestina azotando por cuanto se halla ella robar a los hombres con cautelas disimuladamente; y así mismo por galardón del trabajo que tomaba en ser alcahueta, mando que con su coroza la tengan emplumada públicamente en una escalera subida en mitad de la plaza mayor, hasta tanto que yo mande que la quiten; y que los azotes sean por las calles acostumbradas. Y esta sentencia, por que mejor se ejecute, quiero que a la hora vayas a llamar al pregonero; que aquí te esperaré. (Gómez de Toledo XL, 2016: 632)

Este largo parlamento del corregidor resume lo que a continuación se desarrolla con gran lujo de detalle de forma dialógica. Primero el corregidor manda al pregonero que "la pongas en la orden que se requiere para cien azotes» y que "la pongas en la cabeza una coroza de papel, que signifique el oficio que ha tenido, y la emplumes lo mejor que supieres» (Gómez de Toledo XL, 2016: 632). A pesar de las protestas de Celestina el pregonero insiste en que ella se desnudara para "darte un jubón de azotes, y con esta mitra emplumarte como mereces» Gómez de Toledo XL, 2016: 633). Contestando al corregidor que insiste en que se ponga en práctica cuanto antes el castigo el pregonero contesta: «Ya digo, señor, que por encubridora y alcahueta la mandas azotar y emplumar públicamente. ¡Quien tal hace, que tal pague!» (Gómez de Toledo XL, 2016: 634). Y esto es lo que hace muy a su pesar:

Celestina: ¡Ay, ansiada fue yo! No me des tan crudamente, que me abres las carnes.

Pregonero: Madre, no vuelvas acá la cara, que te acertaré en ella algún azote; que yo mandado soy y tengo de hacer mi oficio conforme a lo que el corregidor me mandó.

27.-En el auto XL, Recuajo y Grajales han matado a Areúsa por tener una relación con Bravonel: «GRAJALES: ¡Toma!, jtoma esta que faltaba para tu fin! RECUAJO ¿Acabástela ya de matar? Grajales: Vesla ahí tendida. Mírala el pulso, que ella tiene su pago» (Gómez de Toledo XL, 2016: 627). 
BALANTES: ¿Para qué vas tan apriesa? Que la gente no entiende lo que pregonas, ni veen los azotes que la das.

Pregonero: Por eso estamos ya en la plaza, a do la verán bien.

Balantes: Atiéstale bien la coroza y súbela en esa escalera.

Celestina: ¡Señor alguacil, por las plagas de Dios te pido que, notando cuán aplagada estoy, mandes a este verdugo que no me afrente más!

BALANTES: Excusado es revocar la sentencia que una vez por el corregidor es dada. Por tanto, súbela presto y átala muy bien.

Celestina: ¡Oh negra fue mi dicha, que todavía tengo de subir! Injuriadme con cuantos vituperios quisierdes, que aparejada estoy a cuanto me viniere; pues jmal pecado!, no puede ser el cuervo más negro que sus alas.

Pregonero: A buena fe, señor, que ella está tan bien que, por aire que haga, no se le quite la borra, ni por fuerzas que ponga, se desate de la escalera.

BALANTES: Ora, vámonos, que extremadamente queda. Y dejemos a los mochachos, que vienen ya [a] pasar tiempo con su merced.

Mоснасно: ¿Qué dignidad es esa, madre honrada? En buena fe, que es larga la mitra, y si tan grande es el obispado, no te faltará renta. (Gómez de Toledo XL, 2016: 635)

Este diálogo insinúa, por una parte, las relaciones entre los ejecutantes de una justicia corrupta y el mundo del hampa, y, por otra, la paulatina pérdida de la influencia de Celestina.

Como destaca Hinrichs $(2011,90)$, se trata del «most deliberately narrated of all the affronts she suffers, and occupies the longest auto of the novel». Está en lo cierto Criado de Val cuando observa que no «tenemos a mano nada similar para hacernos idea de cómo actuaba la justicia popular frente a brujas, celestinas y rameras, a esa escena en que Celestina pasa emplumada, sin demasiada tragedia, entre chicos y gente de pueblo» (1976: XLIX). La forma caleidoscópica en la que se presenta esta humillación de la protagonista constituye el último paso de la degradación de la alcahueta antes de que muriera en el penúltimo auto de la obra. El lector se entera de lo sucedido -tras un grito de Celestina ${ }^{28}$ - por el coro 
de los vecinos que comentan los detalles truculentos - la masa cerebral esparcida en el suelo como en la obra de Rojas ocurrió con Calisto ${ }^{29}-$ y pronuncian un obituario poco halagador:

VeCinos: [...] ¡Oh Celestina, y cuán mal has vivido pues tan mal acabaste! Creed, señores, que toda persona que no es buena en la vida no tiene verdadera ni natural muerte. ¡Cuántos mancebos ha robado! ¡Qué de viejos ha embaucado! ¡Cuántas quistiones ha urdido! ¡Qué de muertes ha causado! ¡Qué falsos hechizos hacía! ¡Qué nobles doncellas ha engañado! ¡Que innumerables mozas ha perdido! ¡Qué recogidas viudas ha deshonrado! ¡Cuántas astucias, cuántas cautelas cuántos embustes hacía para hacer sus enredamientos! ¡Oh mundo, que no sé qué diga de ti, sino que la prosperidad que das es poca, y aunque al parecer alegra, al gustar amarga! Ciertamente tus bienes son como píldora que por de fuera está dorada, $y$, debajo de aquella sotil tela que reluce, tiene el horrible acíbar que es amarguísimo; ansí que lo mucho amargo priva a lo poco dorado. Decírnoslo porque si esta triste se vía próspera un día con lo que la daban, diez días la víamos maltratada y herida de los que la perseguían. ¡Oh mundo, y cómo prometes mucho y das poco! ¡Cómo puedes con halagos y justicias con crueza! ¡Cómo das placer a palmos y pesar a varas! No sabemos de ti decir, por tener tanto que decir, más de que eres mentiroso, erez falaz, eres infame; finalmente, en todas tus cosas eres inicuo. (Gómez de Toledo XILIX, 2016: 682) $)^{30}$

29.- «Vecinos: ¡Santísima Trenidad!, jy cuántos pedazos se la hizo la cabeza, que todos los sesos tiene entre las piedras! Mas cayendo desde aquellos corredores, claro está que había de fenecer su ansiada vida» (Gómez de Toledo XILIX, 2016: 681). Felides repite el detalle funesto cuando informa a su criado del fallecimiento de Celestina: «Porque me dicen que, demás de hallar[la] las piernas y brazos quebrados por ser tan alta la caída, la hallaron su cabeza repartida y machucada entre las piedras; de arte que el remedio que tuvo y tiene es hacerle la mortaja» (Gómez de Toledo L, 2016: 684). Véase para el paralelismo con la obra de Rojas asimismo Heugas : «Il [i.e. Gaspar Gómez] a d'abord fait châtier plusieurs fois la vieille et l'a fait mourir dans une chute qui emporte avec soi un peu de symbolisme de la chute de Calisto» (1973: 570).

30.- Véanse al respecto García Valiente \& Martínez Pérez, quienes subrayan que "pese a que Gaspar Gómez no introduce largos sermones eruditos, sí incluye grandes discursos de carga moralizante y reprobadora, como por ejemplo los que realizan los vecinos tras la muerte de Areúsa (y que parece un resumen moral de los atropellos de Celestina [...] o ante el cadáver de la vieja alcahueta [...], y que tiene como receptores al mundo y a Fortuna, recordando los plantos que realizan Pleberio o Eubulo para cerrar otras obras del ciclo celestinesco» (2019: 266-267). 
Como subraya Heugas (1973: 55) «Gaspar Gómez qui, dans son œuvre, avait passablement avili la vieille avait au moins compris qu'il est des morts qu'il faut tuer deux fois». El investigador francés está en lo cierto diciendo que el continuador había degradado a la tercera Celestina, pero quizás habría que añadir que al mismo tiempo la había despojado de todas las defensas des las que disponían sus antecesoras. Podría decirse que la trama alrededor de la vieja alcahueta es el relato de la agonía de un personaje moribundo. $\mathrm{Al}$ igual que la Lozana andaluza, una diseasing healer en palabras de McInnis Domínguez (2011), la tercera Celestina no es solo curandera, sino también y sobre todo paciente.

\section{La medicina en La tercera Celestina}

\subsection{Celestina, paciente mal curada}

Las agresiones que sufre la tercera Celestina dan pie a una especie de historial clínico, en el que el autor hace particular hincapié en cómo se llevan a cabo las curas que al fin y al cabo no surten el efecto deseado. Cuando Elicia y Areusa hallan a Celestina malherida e inconsciente en la calle después del ataque de Pandulfo y Rodancho deliberan cómo acudir a la vieja:

ELICIA: ¡Amarga fue ella, que no va en su mano! Bueno será atarla esta cuerda muy recio a los pulgares, que podrá ser que aproveche.

AReúsA: Por más probado tenía ella, dejando aparte el rociar con agua y trabar de las orejas, dar un fuerte humo a las narices de plumas de perdiz o gallina.

Elicia: Ese aparejo no le tenemos aquí. Y demás de esto, yo la oía decir muchas veces que era experimentada cosa meter un palico de ruda por las narices, y a falta del otro, cualquiera.

Areúsa: Pues vees que es bueno, ¡hazlo!

ELICIA: ¡Señora!, jah, señora tía!

Areúsa No la metas tanto, que es miembro ese de donde no ha de haber mucha causa para salir sangre.

ELICIA: Mira si es mala la experiencia, que, ipor mi salud!, ya extiende las manos. (Gómez de Toledo XIII, 2016: 452)

Las muchachas enumeran una serie de remedios populares empezando por una cuerda en los pulgares que se utilizaba - según documenta Barrick (1973: 481, nota 595) — contra las hemorragias nasales, una 
molestia que no aflige a la mujer desmayada. También los otros remedios están completamente fuera de lugar como el olor a pluma quemada, que se suponía de gran ayuda contra el mal de madre ${ }^{31}$ o la ruda que se empleaba en exorcismos, además de ser recomendado asimismo contra el dolor uterino ${ }^{32}$. Para cualquiera que reconociera lo inapropiado de los tratamientos propuestos, no sorprende que la alcahueta insiste en que quiere estar sola y curarse sin ayuda ajena con sus 'ungüentos' ${ }^{\prime 3}$. Nos las habemos por lo tanto con una especie de chiste privado entre lectores con ciertos conocimientos médicos.

Asimismo, cuando Celestina se queda desmayada en la calle después del segundo castigo en el auto XXVI el remedio es casi peor que la enfermedad. Esta vez son los rufianes Grajales y Bravonel quienes encuentran a la mujer inconsciente y le aplican golpes y patatas pare que volviera en sí:

Grajales: Tiene frío el rostro, y los pulsos que no andan, iquiere que responda!

Bravonel: ¡A pesar de Gilberto con quien te vistió! ¿Por qué no puedas volverla?

Grajales: ¡Buena disimulación es esta! ¡Como si fuese en su mano ni en la mía el sanarla!

Bravonel: De esta suerte se le ha de dar salud, que no trabándola de los dedicos.

Grajales: ¡A buena fe, que antes de mucho le des el fin a la desastrada si tales golpes das con su triste cuerpo!

BraVonel: Más alto; que yo la tengo de arrojar estotra vez segunda; iy a mí el cargo si a la tercera vez no fuere vuelta y sin peligro de la vida!

Grajales: Haz lo que quisieres; y si la matares, tu alma en tu palma.

BraVonel: No hayas miedo, y mira cómo vuelve con esta mano que la daré agora. (Gómez de Toledo XXVI, 2016: 548)

En esta escena no es solo la incapacidad manifiesta, sino la actitud violenta de los dos hombres que presentan a la protagonista como ser indefenso que depende de la ayuda de quienes sólo a regañadientes la proporcionan.

31.- Véase Barrick, quien recuerda que "Celestina recommended "humo de plumas de perdiz" as a cure for mal de madre» (1973: 481, nota 596); véase para este paralelismo con la obra de Rojas, Esteban Martín (1987: 9).

32.- Véase Barrick (1973: 481, nota 596).

33.- «No es necesidad; sino que os salgáis fuera por que repose un poco; que yo tengo ungüentos con los cuales seré breve guarida» (Gómez de Toledo XIII, 2016: 454). 
Únicamente las vecinas que acuden para curarle la herida en la cara infligida por el paje Albacín muestran una actitud caritativa y ciertos conocimientos prácticos:

Celestina: ¡Es mi ansiada postremería!

VeCINA: Hora, deja el llorar para después; y curémoste, que te desangras mucho.

Celestina: Meteme en mi casa; que con una clara de huevo me curaréis.

VeCina: Sea ansí; que ves aquí estopas y un par de ellos, que traíamos en las mangas como vimos que estabas herida.

Celestina: Llevame quedo; que me matáis.

Vecina: Asegura las manos. Pondrémoste ya algo en esta cara; que seis o siete puntos habías menester. (Gómez de Toledo XXXVII, 2016: 611)

Fue el cirujano Teodorico de' Borgognoni quien empezó a utilizar en el siglo XIII la clara del huevo para tratar las heridas ${ }^{34}$.

En el auto XXII, Celestina se presenta en casa de Paltrana con el pretexto de necesitar "algunas enjundias para una mixtión que tengo de hacer para ablandar y extender los niervos» (Gómez de Toledo XXII, 2016: 517). El listado es en extremo largo y la madre de Polandria se preguntará con razón "¿y qué zurujano ordenó receta tan larga?»(Gómez de Toledo XXII, 2016: 517). Los «untos» enumerados no pueden responder a ninguna preparación medicinal:

Celestina: Señora, pues eres contenta que lo diga, ellos son enjundias de gallina y capón y ánade y ansarón, unto de tasugo y de caballo y de culebra y de víbora, buche de garza, unto de conejos y algunas cañas de vaca. Estos me harás merced, si posible fuere, que me busque un criado de casa [...] De poquillo es lo que falta, sino que tengo de buscar por toda esta tierra y sus rededores hasta media onza de unto de hombre. Y maté ayer un gato, ique conciencia se me hizo por haber seis años que le criaba!; mas habrías placer si vieses el unto que tenía. Y de la botica trairé

34.- "Teodorico (1205-1298) pertenecía a la orden de los dominicos y fue el primero en emplear "simples" para tratar las heridas; estos simples — clara de huevo y agua de rosasfacilitaban la curación por primera evitando frecuentemente la supuración que era admitida tradicionalmente como fase normal de la curación, como lo sostenían Rogerio de Palermo (1170-1200) y su asociado Rolando de Parma (i-1258) que enseñaban en Salerno». Finkielman (2004: 561); véase también Haeger (1993: 82). 
aceite de bayas y de eneldo y de almendras, y dialtea y ungüento marciatón y otros polvos que le he de mezclar de muchas cosas. Y ansí mismo he de hacer, para lavarla primero a manera de baño, un cocimiento de una cabeza de carnero negra, con una multitud de yerbas que tengo yo secas todo el año en mi casa, las cuales cojo cada mañana de San Juan. (Gómez de Toledo XXII, 2016: 517-518)

Barrick (1973: 506-508) se empeña en sus amplias anotaciones a este parlamento de Celestina en documentar el uso farmacológico de los ingredientes enumerados por Celestina con particular hincapié en sus beneficios ginecológicos. Al igual que Polandria dudo de que los ingredientes enumerados por Celestinas tengan que ver con una receta concreta. Nos las habemos más bien con una escritura en forma de lista, procedimiento tan caro a un médico escritor como François Rabelais ${ }^{35}$, que Dubois explica con «un plaisir du sériel» (1985: 37) de esta época. Como observa Belknap, "the list is a device that writers have frequently employed to display the pleasurable infinitude of language» (2004: 2). La enumeración de los untos en la Tercera Celestina recuerda los 'recetarios' de la Tragicomedia de Rojas o de La Lozana Andaluza, pero la función de la lista es diametralmente opuesta. No sirve para ilustrar los conocimientos de la protagonista, sino para ilustrar de que carece. Tiene que pedir los productos a Polandria porque evidentemente no los tiene. Y tampoco tiene el don del habla de la Celestina de Rojas o de la Lozana Andaluza. No consigue despertar la compasión de Paltrana con sus peticiones y, en última instancia, su estrategia retórica no acaba de funcionar con la madre de la novia.

A lo largo de la obra, Celestina sufre las consecuencias de la primera agresión y su movilidad está considerablemente restringida. En el auto XVI se describe con gran lujo de detalle cómo es asistida al bajar la escalera por cuatro personas:

Celestina: Hijo, empezá a bajar adelante; que, pues os hice venir, no soy tan perezosa que me detendré en ello.

Areúsa Daca la mano, y de esotro brazo te llevará Elicia; e irás por esta escalera como novia.

Celestina: No abajéis tan apriesa; que según la fuerza yo tengo en las piernas, poco ha menester para rodar todas tres.

35.- Véase para las listas de Rabelais Bonhomme: «Par delà leur diversité, les listes de Rabelais s'inscrivent dans un même principe esthétique: celui de la profusion - ou de la copia, à travers laquelle son énergie vitale se traduit par une inflation verbale à la hauteur de son imaginaire hors du commun. Surtout, l'interaction entre le listage et l'énonciation parodique revêt une valeur exemplaire chez Rabelais» (2013: 208). 
Elicia Descansada estoy, que hemos descendídote sin quistiones.

SigerIL: Mira si irás bien en la silla asentada, porque en las ancas será imposible que puedas llegar.

Celestina: Pues pon algo en esos estribos para en que ahirme.

SigerIL: En esta tablica pondrás los pies, que es propia.

Celestina: Ea, ayudadme todos cuatro a subir.

Sigeril: Elicia, ten tú esa mula, y Areúsa le adobará las haldas en la silla; e yo y tú, Perucho, tendremos estas tablas, y jarriba con ella!

AreúsA ¿Sientes algo?, que parece que te congojas. (Gómez de Toledo XVI, 2016: 477)

La importancia que se le da a la minusvalía de Celestina se demuestra también por el hecho de que la propia discapacitada, en una conversación con Felides, se refiere a sus dificultades motrices ${ }^{36}$. En su estudio sobre la representación de minusválidos en textos españoles de la Edad Media, Scarborough observa que «the impaired individual was either perceived as having been punished by God for a sin he/she had committed or, conversely, as a potential recipient of divine reversal of impairment in response to prayer and sincere belief in a cure» $(2017,11) .{ }^{37}$ Es obvio que en la Tercera Celestina la protagonista sufre físicamente las consecuencias de su depravación moral.

\subsection{Celestina, curandera}

En la primera modernidad, coexisten dos sistemas de cura diametralmente opuestas. Por una parte, la medicina oficial, masculina, y por la otra la medicina popular, representada por mujeres. Un campo de actividad tradicional de las curanderas femeninas eran los cuidados obstétricos y ginecológicos ${ }^{38}$. A diferencia de las protagonistas de Fernando de Rojas, Feliciano de Silva o Francisco Delicado, la tercera Celestina no se dedica

36.- «Celestina: ¡Ay, desventurada fue yo! ¡Y no miras mi negra pierna!, que paso con ella tal pasión que, para mudarme dos o tres personas de un lugar a otro, he de juntar a gritos la vecindad, cuanto más subir escaleras». (Gómez de Toledo XVIII, 2016: 488)

37.- Véase también el estudio de la minusvalía en la literatura inglesa de los primeros tiempos modernos Hobgood y Houston Wood (2018).

38.- Como observa Green «the production and the use of knowledge on the female body was gendered» (2008: 169) a lo largo de la edad Media y en los primeros tiempos modernos. 
a curar el «mal de madre» o a "rehacer vírgenes»" ${ }^{39}$. Como ha demostrado Gutiérrez Rodilla, "la actividad de las sanadoras, a pesar de lo que algunos discursos contemporáneos han querido hacer creer, no se limitó a la atención a mujeres y niños, en el tradicional ámbito femenino de la asistencia al parto y procesos ginecológicos: veían a pacientes de ambos sexos y de todas las edades para efectuar prácticas quirúrgicas, pero también para atender cuadros de medicina general, así como para preparar remedios terapéuticos» (2015: 129). Muchas de las curanderas literarias se dedican efectivamente a un amplio abanico de pacientes con patologías distintas, máxime en obras escritas por médicos como es el caso de La Lozana andaluza y, quizás, de la Tercera Celestina.

Cuando, en el auto XVII, el alguacil Castaño quiere detener a Celestina por estar fuera de su casa a deshora ${ }^{40}$, ella intenta excusarse con un supuesto dolor de muelas de Felides que no deja de recordar el problema dental de Calisto que se inventa la protagonista de Rojas hablando con Melibea. El razonamiento de Celestinas es interesante por la descripción de la medicina popular:

Lo que quiero decir es que soy una vieja pecadora, y Dios por su infinita piedad me concede mis oraciones en sanar a quien curo, aunque no por mis merecimientos, es por su gran misericordia. Ansí que Felides, según me informó su criado que está presente, se ha sentido desde prima noche muy congojado de las muelas, y para que le haga un cocimiento que suelo usar muy provechoso, me envió esta mula, con Sigeril y el otro mozo que se fue, para que me llevasen; que ya ves que, aunque quisiese argüir otra cosa, mi edad me salva. (Gómez de Toledo XVII, 2016: 481)

Son los mismos procedimientos de curación por medio de la palabra de las que hace gala la Lozana ${ }^{41}$. Se trata del mismo «healing knowledge that

39.- Hay una sola referencia a la cura «de la madre» en un diálogo entre la protagonista y Sigeril sobre las virtudes de los distintos vinos: «Madrigal se nombra por el salutífero vino que tiene para las mujeres que solemos estar enfermas de la madre, porque, jen mi ánima!, jamás hallé más provechoso emplasto ni polvos ni otras unturas ni medicinas para este mal como una copa de esto puro». (Gómez de Toledo XXXIII, 2016: 590)

40.- "CAStaño: No más de que a esta hora son vedadas las mujeres que anden, pues tiene tiempo en el día» (Gómez de Toledo XVII, 2016: 483).

41.- «Yo sé ensalmar y encomendar y santiguar cuando alguno está aojado, que una vieja me vezó, que era saludadera y buena como yo. Sé quitar ahitos, sé para lombrices, sé encantar la terciana, sé remedio para la cuartana y para el mal de la madre. Sé cortar frenillos de bobos y no bobos, sé hacer que no duelan los riñones y sanar las renes y sé ensolver sueños, sé conocer en la frente la fisionomía y la quiromancia en la mano, y prenosticar» (Delicado 2013: 215). Véase al respecto McInnis "Lozana mixes both empirical and "superstitious" medicine in her diverse practice that mimics that of real female healers, particularly subaltern female healers of the day, who 
functioned primarily in the oral register» que estudia Cabré (2008: 36) como dominio femenino.

En el auto XXXVI se produce un diálogo muy interesante entre Sigeril y Celestina que gira entorno del antagonismo entre curanderas y médicos con formación académica que es una problemática a la que Francisco Delicado concede bastante espacio en su Retrato ${ }^{42}$. Al igual que la Lozana ${ }^{43}$, la tercera Celestina insiste en que la gente la persigue para ser curada de ella ${ }^{44}$. El comentario de Sigeril es susceptible a ser leído como alegato en favor de una ciencia médica empírica que se basa en la "experiencia» de cara a la medicina universitaria:

Por mi vida, que no te ha de pesar de hacer bien, pues puedes; que loores debrías de dar a Dios, que te da buena manderecha en sanarlos; que si no llaman a médicos sabios, es porque la experiencia es madre de todas las cosas, y como tú la tienes, quieren dar antes un ducado a ti por tu fama que un real a los doctores por su ciencia. (Gómez de Toledo XXXIII, 2016: 604)

El valor de la medicina se mide en términos económicos ${ }^{45}$ : Según observa el criado, la gente estaría dispuesta a pagar diez veces más para los tratamientos de Celestina que para aquellos de un médico ${ }^{46}$. Se sobreentiende que se trata de un mundo al revés en una época, en la que los servicios de los sanitarios sin formación académica eran muy mal remunerados ${ }^{47}$.

often held numerous professions in order to make a living. It was precisely this mix and their lack of theoretic training that caused all female healers, regardless of ethnicity, to be marginalized from "legitimate" medicine» (2011: 323).

42.- Véase al respecto Strocchia: "Crucial to the marginalization of women as healers was the denigration of their empirical knowledge and know-how by university-trained physicians and guildsmen eager to establish superior professional competencies. Learned medical practitioners were known to scoff at the kind of practical knowledge women healers possessed, since it was not grounded in text-based, academic medical theory» (2014: 496-497).

43.- Véase el mamotreto LIX, en el que la protagonista habla «con dos médicos, y el uno era cirúgico». (Delicado 2013: 295)

44.- «Por tu vida y mía, que quiero ir a visitar a una enferma que ha enviado cincuenta veces a rogarme que la vea; que bien puedo decir que estó aborrida con tantas negras curas como tengo, que persona no sabe llamar ya a médico de ninguna enfermedad que tengan, sino Celestina acá, Celestina acullá». (Gómez de Toledo XXXIII, 2016: 604).

45.- En su artículo sobre la ganancia en la materia celestinesca, Herrera (1998) no presta atención a este lugar.

46.- Recuérdese que un real «un ducado (3, 386 gr. de oro) equivale a [...] 10 reales [...] o a 350 maravedís» (Delicado 2013: 388, nota complementaria 22.31). Tanto el lector como Sigeril dudan de la afirmación de Celestina que insiste en que «jamás me acuerdo llevar un maravedí por cura que hiciese a rico ni a pobre». (Gómez de Toledo XXXIII, 2016: 605)

47.- Vons observa a propósito de las parteras en la Edad Media que «leurs fonctions d'auxiliaires étaient peu rétribuées; c'est ainsi que plusieurs comptes d'archives de municipalités dans les Flandres, comme ceux d'aumônes à Tours, font apparaitre des sommes versées 


\section{A modo de conclusión: la Tercera Celestina ¿obra de un médico?}

¿Es posible que Gaspar Gómez de Toledo hubiera sido un médico? Hay una serie de argumentos en favor de esta hipótesis. Por una parte, el gran interés en cómo curar las heridas de los personajes y por otra el gran número de alusiones de varia índole al arte de Esculapio: Celestina utiliza argumentos pseudo-médicos para justificar su consumo de vino ${ }^{48}$. El hortolano Penuncio elogia los beneficios para la salud del aire fresco de la mañana ${ }^{49}$. Felides compara la ayuda que le presta Celestina con la relación médico paciente ${ }^{50}$. Poncia utiliza metáforas del campo semántico de la medicina que Sigeril no entiende:

PONCIA Mejor dijeras dos porradas, según empiezas ya a descascar.

SigeRIL: Señora, ¿cómo puede ya hacer principio el que está propinco al fin?

PONCIA Y aun eso es lo que yo quería decir, ique me tienes con el regüeldo de la purga enhadada y me tornas a dar los jarabes!

SigeriL: De verdad, nunca he sido boticario. No sé cómo te doy jaropes.

PoNCIA Pues no me entiendes. Sabe que lo que digo es que harto basta el hartura que me has dado con tus negros requiebros hasta aquí, sino que agora vuelvas de nuevo; que vosotros, como cuanto hacéis en la mocedad procede de ignorancia, no se ha de parar mientes en nada, pues ello y el aire se pondera por un igual. (Gómez de Toledo X, 2016: 430) (11 $^{51}$

à des sages-femmes déclarées pour examiner les nouveau-nés abandonnés et leur donner les premiers soins» (2008: 224).

48.- "iCalla, hijo, que ansí goces no podrás creer las malicias de Elicia, que no puede ver y oír y callar!; pues sabernos que así como al enfermo, por no poder comer, le sacan la sustancia de las aves que beba; por el consiguiente, a quien tiene mis días, pues no puede mascar, le es lícito beber algunas vececillas de vino para esforzar la virtud». (Gómez de Toledo XXXIII, 2016: 588-589).

49.- «de mañana huelga hombre en este tiempo recebir tan suave y frío aire, que todos los médicos afirman que es saludable» (Gómez de Toledo III, 2016, 373). Barrick interpreta el consejo como alusión a un lugar del De Aeribus, Aquis et Locis, en el que Hipócrates «speaks of cities facing cold winds as being generally healthier than those facing warm winds» (1973: 427, nota 149).

50.- «El propio médico ya sabes que despacio quiere oír la relación de la enfermedad para que, conforme a ella, ordene la medicina» (Gómez de Toledo XVIII, 2016: 488).

51.- Para el significado de 'regüeldo' véase el comentario de la edición de Barrick: «Regüeldo significa corrientemente 'eructo'; aquí, por traslación, 'exhalación, mal olor'» (1973: 470, nota 486). 
El propio criado habla en otro lugar sobre los beneficios de los conocimientos médicos: «Digo que bien sabemos que Dios es sobre todo; empero, que el saber de las gentes ayuda a conservar nuestro cuerpo humano de los humores corruptos que causan dolencias y malas disposiciones» (XXXIII, 2016: 606). Y hasta el rufián Rodancho habla —al intentar apaciguar la discusión entre Pandulfo y Quincia - de la ira en términos de patología humoral rústica: "Que estos hombres coléricos, cuando les sube el humo a la chiminea, malo es de apagar»(VII, 2016: 411).

Y hay más, como ha estudiado Alison Klairmont Lingo para Francia, entre las varias tipologías de sanadoras se halla la vieja de índole celestinesca que en los primeros tiempos modernos es objeto de la escritura satírica de médicos:
Also confounded with the witch were the prostitute and/or "old woman». [...] Usually this type of healer was an elderly retired prostitute, sometimes simply called an old woman (vielle, vekke, anniculla) who through her life work had become knowledgeable in matters of femi- nine appearance, contraception, abortion and midwife- ry. While moralists attacked such healers in the Mid- dle Ages, it was the physician who took up their pens against these «maquerelles» (madames) and "old women" in the early modern period (1986: 596) ${ }^{52}$.

Recuérdese, además, que entre los primeros demonólogos había toda una serie de médicos ${ }^{53}$ : Jean Wier, autor de De praestigiis daemonum (1563), traducido al francés por el galeno Jacques Grévin, o Reginald Scot quien publicó en 1584 The discoverie of witchcraft.

Médico o no, Gaspar Gómez de Toledo no poseía un talento literario excepcional, pero ha podido narrar la agonía de su protagonista con tanta convicción que salvó a Celestina de más resurrecciones y muertes.

52.- La historiadora francesa basa sus conclusiones en el análisis de la La police de l'art et science de medecine (1580) de André du Breil y en la Satyre contre les charlatans, et pseudo-médecins empyriques (1610) de Thomas Sonnet de Courval. Véase al respecto asimismo Whaley (2011 55) que constata que Du Breil «claimed that midwives were most likely witches». y que De Courval cuando pone sobre aviso contra los charlatanes «specifically referred to nuns and 'witches', or older women».

53.- Véase Estes (1983: 279) quien sugiere que «the rise of the craze could be traced to the revolution in medical thinking that marched beside it so closely». 


\section{Bibliografía}

\section{Textos}

Delicado, Francisco (2013), La Lozana Andaluza, eds. Jacques Joset \& Folke Gernert, Madrid, Real Academia Española.

Gómez de Toledo, Gaspar (1973), Tercera parte de la tragicomedia de Celestina, ed. Mac E. Barrick, Philadelphia, University of Pennsylvania Press, 1973.

- (2016), Tercera parte de la tragicomedia de Celestina, en Segundas Celestinas, ed. Rosa Navarro Durán, Madrid, Castro.

Kramer, Heinrich \& Jakob Sprenger (2006), Malleus maleficarum: El martillo de los brujos, Barcelona, Reditar Libros.

RojAs, Fernando de (y 'antiguo autor') (2000), La Celestina. Tragicomedia de Calisto y Melibea, eds. Francisco J. Lobrera y Guillermo Serés, Paloma Díaz-Mas, Carlos Mota e Íñigo Ruiz Arzálluz, y Francisco Rico, Barcelona, Crítica.

Silva, Feliciano de (1988), La Segunda Celestina, ed. Consolación Baranda, Madrid, Cátedra.

\section{Estudios}

Allaigre, Claude (2004), "Las ciento e veinte e cinco personas que hablan del Retrato de la Lozana Andaluza», en Siglos dorados: homenaje a Agustín Redondo, ed. Pierre Civil, Madrid, Castalia, vol. 1, pp. 15-31.

Baranda Leturio, Consolación \& Ana Vian Herrero (2007), "El nacimiento crítico del "género" celestinesco: historia y perspectivas", en Orígenes de la novela: estudios. Ed. Raquel Rodríguez Gutiérrez Gutiérrez Sebastián, Borja. Santander: Sociedad Menéndez Pelayo, pp. 407-482.

Baranda Leturio, Consolación (2017), "Las comedias del ciclo celestinesco. Segunda comedia de Celestina y Comedia Selvagia», en La escritura inacabada. Continuaciones literarias y creación en España: siglos XIII a XVII. Eds. David Roblin Alvarez \& Olivier Biaggini, Madrid, Casa de Velázquez, pp. 69-85.

BARrick, Mac E., "Introduction» (1973), en Gaspar Gómez de Toledo, Tercera parte de la tragicomedia de Celestina, ed. Mac E. Barrick, Philadelphia, University of Pennsylvania Press.

Belknap, Robert E. (2004), The List. The Uses and Pleasures of Cataloguing, New Haven / London, Yale University Press. 
Bettella, Patrizia (2005), The ugly woman. Transgressive aesthetic models in Italian poetry from the Middle Ages to the Baroque, Toronto, University of Toronto Press.

Bonhomme, Marc (2013), "Liste et énonciation parodique chez Rabelais», en Liste et effet liste en littérature. Eds. Sophie Milcent-Lawson, Michelle Lecolle \& Raymond Michel, Paris, Classiques Garnier, pp. 195-208.

BotTa, Patrizia (2002), "La Celestina vibra en La Lozana», Cultura Neolatina, 62, pp. 275-304.

CABRÉ, Montserrat (2008), «Women or healers? Household practices and the categories of health care in late medieval Iberia», Bulletin of the history of medicine, 82, pp. 15-51.

Cirillo, Teresa (1988), "Plurilinguismo nelle commedie di Torres Naharro", Annali Istituto Universitario Orientale, Napoli, Sezione Romanza, 30, pp. 173-221.

CRIADO DE VAL, Manuel (1976), «Introducción», en Fernando de Rojas; Feliciano de Silva; Gaspar Gómez de Toledo; Sancho de Muñón, Las Celestinas, ed. Manuel Criado de Val, Barcelona,Planeta.

DuboIs, Claude-Gilbert (1985), L'imaginaire de la Renaissance, Paris, PUF.

Diochon, Nicolas \& Cécile Iglesias (2011), «"E más son de las mugeres viejas e pobres que tienen recurso al demonio": el estereotipo de la vieja bruja. Entre demonología y literatura", en De la caduca edad cansada. Discursos y representaciones de la vejez en la España de los siglos XVI y XVII, ed. Nathalie Dartai-Maranzana, Saint-Étienne, Publications de l'Université de Saint-Étienne, pp. 111-149.

Esteban Martín, Luis Mariano (1987), "Huellas de Celestina en la Tercera Celestina de Gaspar Gómez de Toledo", Celestinesca, 11, pp. 3-20.

Estes, Leland (1983), "The Medical Origins of the European Witch Craze: A Hypothesis", Journal of Social History, 17, pp. 271-284.

FinKIELMAN, Samuel (2004), «La Universidad de Bolonia y la olvidada cirugía medieval italiana», Medicina 64, pp. 559-562.

García Valiente, Luis \& Antonia Martínez Pérez (2019), «El uso de la erudición en las continuaciones argumentales de La Celestina», Estudios románicos, 28, pp. 259-268.

Gernert, Folke (1999), Francisco Delicados "Retrato de la Lozana Andaluza» und Pietro Aretinos "Sei giornate». Zum literarischen Diskurs über die käufliche Liebe im frühen Cinquecento, Genève, Droz.

- (2018a), "cuanto va de la excellencia del alma a la del cuerpo: La legibilidad del cuerpo humano en la Segunda Celestina de Feliciano de Silva», Celestinesca, 42, pp. 421-442.

- (2018b), Lecturas del cuerpo. Fisiognomía y literatura en la España áurea, Salamanca, Universidad de Salamanca.

Green, Monica Helen (2008), Making women's medicine masculine: the rise of male authority in pre-modern gynaecology, Oxford, Oxford University Press. 
GutiérRez Rodilla, Bertha M. (2015), "Las mujeres y la medicina en la Edad Media y el primer Renacimiento", Cuadernos del CEMyR, 23, pp. 121-135.

Haeger, Knut (1993), Historia de la cirugía, Madrid, Raíces.

Herrera, Francisco José (1998), "Sobre la ganancia en la materia celestinesca", Lemir: Revista de Literatura Española Medieval y del Renacimiento, 2 , sin $\mathrm{pp}$.

Heugas, Pierre (1973), La Célestine et sa descendance directe, Bordeaux, Institut d'études ibériques et ibéro-américaines.

HinRICHs, William Hastings (2011), The invention of the sequel. Expanding prose fiction in early modern Spain, Woodbridge, Tamesis.

HoBGOOD, Allison \& David Houston Wood (2018), «Early Modern Literature and Disability Studies», en The Cambridge Companion to literature and disability. Eds. Clare Barker, and Stuart Murray. Cambridge, Cambridge University Press, pp. 32-46.

Juárez-Almendros, Encarnación (2018), Disabled Bodies in Early Modern Spanish Literature: Prostitutes, Aging Women and Saints, Oxford, Liverpool University Press.

Klairmont Lingo, Alison (1986), "Empirics and Charlatans in Early Modern France: The Genesis of the Classification of the "Other" in Medical Practice», Journal of Social History, 19.4, pp. 583-603.

LIZABE, Gladys (2010), «La vejez en la literatura medieval española: miradas desde La Celestina», en Actas del XIII Congreso Internacional de la Asociación Hispánica de Literatura Medieval: (Valladolid, 15-19 de de septiembre de 2009). In Memoriam Alan Deyermond. Eds. José Manuel Fradejas Rueda, Deborah Anne Dietrick et al., Valladolid: Universidad de Valladolid, pp. 1131-1146.

McInnis DomíngueZ, Meghan (2011), "The diseasing healer: Francisco Delicado's infectious La Lozana andaluza», eHumanista: Journal of Iberian Studies, 17, pp. 311-333.

Menéndez Pelayo, Marcelino (1943), Orígenes de la novela. Primeras imitaciones de la "Celestina". Edición digital a partir de Edición nacional de las obras completas de Menéndez Pelayo. Vol. 16, Madrid, Consejo Superior de Investigaciones Científicas.

NúÑez Rivera, José Valentín (2010), "El "ojo del cielo”. Escatología y picaresca en el Buscón", en Fragmentos para una historia de la mierda: cultura y transgresión. Eds. Luis María Gómez Canseco, \& Jaime Alvar Ezquerra, Huelva: Universidad de Huelva.

Pitel, Anne-Hélène (2011), "Ambivalencia de la senectud en las 'hijas' de Celestina: una edad dorada con sabor amargo", en De la caduca edad cansada. Discursos y representaciones de la vejez en la España de los siglos XVI y XVII, ed. Nathalie Dartai-Maranzana, Saint-Étienne, Publications de l'Université de Saint-Étienne, pp. 187-214. 
Sanz Hermida, Jacobo S. (1994), "Una vieja barbuda que se dice Celestina: Notas acerca de la primera caracterización de Celestina», Celestinesca, 18, pp. 17-34.

Scarborough, Connie L. (2017), Viewing Disability in Medieval Spanish Texts (Disgraced or Graced), Amsterdam, Amsterdam University Press.

Salvador Miguel, Nicasio (1984), "Huellas de La Celestina en La lozana andaluza", en Estudios sobre el Siglo de Oro: homenaje al profesor Francisco Yndurain, Editora Nacional, Madrid, pp. 429-460.

Snow, Joseph T. (2005), "Some Literary Portraits of the Old Woman in Medieval and Early Modern Spain", en "Entra mayo y sale abril»: Medieval Spanish Literary and Folklore Studies in Honor of Harriet Goldberg. Eds. Manuel da Costa Fontes, and Joseph T. Snow. Newark: Juan de la Cuesta, pp. 349-363.

Villagrá Terán, María Montserrat (2013), "La Lozana Andaluza» en el siglo de los humanistas: un retrato que parodia otro retrato, Tesis, Madrid, UNED.

Vons, Jacqueline (2008), «La parole d'une sage-femme: Louise Bourgeois (1563-1636)», en Femmes en médecine. Eds. Véronique Boudon-Millot, Véronique Dasen \& Brigitte Maire, Paris, De Boccard, pp. 223-238.

Whaley, Leigh (2011), Women and the Practice of Medical Care in Early Modern Europe, 1400-1800, New York, Palgrave Macmillan. 
